\title{
TEMPO IN BAROQUE MUSIC AND DANCE
}

\author{
Esther Coorevits \& Dirk Moelants \\ IPEM-Dept. of Musicology, Ghent University, Belgium
}

\begin{abstract}
Recently, there is a growing interest in studies on the relationship between music and movement. Insight in the relation between dance and music is particularly important for the Baroque period, as music and dance were directly related, even if music was not used to dance to. In Baroque dance, particular dance steps and the character of different dance types demand a specific tempo. However, in musical performance practice, the tempo variation can be very large and the link with the original dance movement is often lost. The aim of this study is to compare the interpretations of dancers and musicians in an experimental setting. The study consists of two parts. First, we investigate the influence of dance movement on the interpretation of a series of dances by musicians. The pieces were recorded with and without dance and we compare tempo and timing in the different versions. In the second part, dancers performed a particular choreography on music that varied in tempo. Video analysis and questionnaires were used to evaluate the different performances. These results were compared with the tempo of musical recordings of similar dance types. Results show a clear difference between music and dance performance. Musicians adapt their interpretation when performing together with the dancers and the optimal tempo zone found for certain Baroque dances coincides only partly with the tempi commonly found in music recordings. The direct link between music and movement and its mutual influence illustrates the importance of an embodied approach in music performance, where in this case dance movement gives concrete information for a 'historically informed' performance.
\end{abstract}

\section{INTRODUCTION}

Regardless of style or region of origin, music and dance are closely related art forms. Not only is dance almost always accompanied by music, also do the movements associated with certain musical genres influence the way we interpret and perceive the music. Up to now, scholarly research has focused on either dance or music, mainly based on written sources. Few attempts have been done to shed light on the mutual interaction between dance and music in an actual performance context.

Insight in the relation between dance and music is particularly important for the Baroque period, and this for a number of reasons. First, the direct link between dance practice and music is very important in this era. An important share of the music was composed with the intention to serve as dance music, both in a social context and in a theatrical setting. Second, the influence of dance music is very prominent in other genres: instrumental music often takes dance movements as a model and also in vocal genres as cantatas or oratorios, references to dance movements are prominent. Therefore, the music of the Baroque era cannot be fully understood without insight in the dance practice of that period.

In this paper we present two empirical studies that explore the interaction between dance performance and the interpretation of Baroque music. Empirical studies that deal with historical performance practice are rare. A few studies have focused on specific aspects of timing such as overdotting (Fabian \& Schubert, 2004) or 'notes inégales' (Moelants, 2011), comparing the interpretation of different performers. But the relation with dance movement is not yet taken into account. At the same time, we see a growing interest in studies on the relationship between music and movement in more general terms. The topic appears in different areas, such as musical development (Phillips-Silver \& Trainor, 2005), music education (Campbell, 1991), rehabilitation (Thaut \& Abiru, 2010), musical communication (Moelants, Demey, Grachten, Wu, \& Leman, 2012) or the influence of music on movement (Leman et al., 2013). These studies have given rise to a large spectrum of methods that can be applied to study the relationship between dance and music (Leman \& Naveda, 2010; Maduell \& Wing, 2007). But none of these has placed their research in a historical context, looking at the relation between historical dance and music performance. On the other hand, several studies have stressed the importance of dance for the interpretation of Baroque music but did not look at an actual performance (Franko, 2011; Little \& Jenne, 2001). In this paper we will first go deeper into the relation between Baroque dance and music, give an overview of some aspects of dance which have a crucial influence on the interpretation of the music and present two experiments in which the relation between music and dance is explored in a real performance context.

\section{BACKGROUND}

\subsection{Dance and music in the Baroque era}

During the $17^{\text {th }}$ century, dance reached its status as a serious art discipline in the Western tradition, which, eventually, would lead to the 'romantic' ballet of the $19^{\text {th }}$ century (Franko, 2011). Leading nation in the development of dance as an art discipline was France. Court dancing, refined and graceful in style and technique, symbolized French culture and was considered superior to any other dance form in Europe (Little \& Jenne, 2001). The dissemination of French culture through noble dance was not the least accomplished by French dancing masters who were employed at every notable European court. To quote Pierre Rameau (1725): “There isn't any European court that hasn't employed a French dancing master." Along with the dance, they spread the music accompanying it. Thus, both the European 
aristocracy and court musicians and composers came into contact with French dances and their music. Music theorists of the 17th century encouraged musicians to refine themselves in the art of dancing in order to feel the natural rhythmical flow and pulse of the music (Muffat, 1698).

The chief tools in the dissemination of court dance were the many dance treatises and manuals that were published and spread throughout Europe. In 1700, a dance notation system developed by Pierre Beauchamp was published by Feuillet in his Chorégraphie, ou l'art de décrire la danse (1700). It elaborated an extended and complex dance vocabulary and was the most popular system at that time. Its chief components are symbols to show the movements of the dancers feet and legs, the distribution of these symbols along the dance path where the bars of music are indicated and the corresponding musical tune on top of page that shows how music and dance are related (Pierce, 1998).

The vision of the dancer-choreographers was that writing down dances in a fixed system could ensure the correct and complete transferal of dances from one generation to another (Franko, 2011). The codified steps, path of choreography and its relation to the music do give us a lot of information to apprehend court dance. But at the same time, the complexity can obscure the correct interpretation. Dance masters were aware of this and wrote treatises about the interpretation of dance-notation. Famous examples include Traité de la Cadence (Feuillet \& Pécour, 1704) and Le Maitre à Danser (Rameau, 1725). Two scholars who made a major contribution to research on the relation between Baroque music and dance are Hilton (Hilton, 1977, 1981, 1986) and Little (Little, 1975a, 1975b; Little \& Jenne, 2001).

But the influence of the dance goes beyond actual dance music. During the 17th century, stylized dance music emerged that contained more elaborated melodic and rhythmic traits, intended for concerts without actual dance performance (Spitzer \& Zaslaw, 2005). One of the questions here is whether the original dance practice is still traceable in the performance of these works. Despite the absence of choreography, the two were not entirely disconnected. Both musicians and composers had practical knowledge of ballroom and theatre dance, which inevitably influenced their compositions and performances. J.S. Bach, for example, wrote a large amount of music of which not only the title but also the musical traits imply a connection to French court dancing. On the other hand, very popular dances in instrumental music (e.g. the allemande) were not performed as choreography anymore in the 18th century.

This opens a lot of questions on interpretation, both for dancers as musicians interested in historical performance practice. One of the main problems when dealing with the interpretation of Baroque dance music is the choice of the tempo.

\subsection{Tempo and its relationship to choreography}

Tempo-indications in Baroque music are mostly expressed verbally and by consequence open to interpretation. They can refer to the character, movement or the expression in which the music should be played or performed, for example vivement or gay, andante or allegro (Cyr, 1998). Apart from verbal indications, the time signature or meter of a musical piece bears a connotation of tempo too. In general, the speed of the counting unit (the denominator of the fraction) slows down when the unit gets smaller. A bar in $3 / 2$ is then supposed to be played slower than a bar in $3 / 4$. This way, tempo and meter are closely related to each other, but not equal. When reading tempo-indications, a pitfall is the metric level of the meter the indication is pointing to. A dance could be interpreted slowly at the level of the half note, but livelier on the level of the quarter note. By exploring the metric structure it is possible to find some indications for the tempo and character of the music (Little \& Jenne, 2001). In any case, playing music in the appropriate tempo was considered essential to good musical taste, as Étienne Loulié points out in his Éléments (1696):

"Mais je me flatte que ceux qui ont le goust fin \& qui ont éprouvé combien un Air perd de sa beauté lorsqu'il est executé trop viste ou trop lentement, me sçauront bongré de leur donner un moyen (...) pour en connoître le veritable mouvement (...)"

In dance music, the correct tempo is essential for the character of the dance, the corresponding choreography and the distinction of different dance genres (Donington, 1989). French music theorists were aware of this problem at that time, and developed an instrument to define tempo-indications more exactly, relaying on the movement of a pendulum (de La Chapelle, 1737; l'Affilard, 1705; Loulié, 1696; Meyerhöfer, 1996; Pajot, 1735). Pendulum data were preserved for a small selection of dances, but they are not as unequivocal as our present metronome numbers and the correct interpretation of these data is still under discussion (Harris-Warrick, 1992; Heijdemann, 1984; Hilton, 1981; Jerold, 2010; Kroemer, 2001; Van Biezen, 1984). This is where actual dance practice can give insight in the difficult question of tempo in Baroque dance.

First of all, the tempo of the music should be appropriate for the execution of dance steps, especially the leaps. These can be performed slow or fast, but it is physically impossible to remain suspended in the air infinitely. Also, one measure of music may contain many steps, which would take a dancer more time and thus a slower tempo. In general, Baroque court dance should be performed with an air of effortlessness and elegance, and all dance steps and movements should be fluently merged into each other. A skilled dancer will be able to perform the dance steps more quickly without getting untidy and will not loose the smoothness in performing steps very slowly (Little, 1975b). Also the character of the dance is important for the tempo: choreographies containing sliding steps and few hops bear a more dignified, serious character and therefore will be performed more slowly than choreographies containing many leaps and jumps. The way a specific step is executed or articulated, for example a deep and slow opposite to a fast and crispy plié (bending of the knees), tells a lot about the character of the dance and depends largely on the tempo of the music (Little, 1975a). In the research on Baroque dance music, some scholars already took the notated choreography into consideration (Cobau, 1984; Harris-Warrick, 1992; Hilton, 1977; Little, 1975a; Little \& Jenne, 2001; Qureshi, 1994), but up to now, 
systematic research on actual dance practice is lacking. In this paper, two studies are presented which explore the relationship between tempo, musical practice and dance performance.

\section{EXPERIMENT 1: THE INFLUENCE OF DANCE ON MUSIC PERFORMANCE}

\subsection{Procedure}

The choreography used for this experiment is "The Submission", a ballroom dance created in 1717 by the English dancing master Kellom Tomlinson on music by John Loeillet. It consists of three musical parts, each with its own character, on which one choreography is danced. A slow movement in $3 / 4$ is followed by a lively menuet, also in $3 / 4$, while the last movement is a fast rigaudon in $4 / 4$. Also, the character of the choreography changes with the dance types: The menuet contains the typical pas de menuet and the faster movements contain more lively steps.

A couple of experienced baroque dancers performed with a musical ensemble consisting of a violin, a viola, a viol and a harpsichord. Initially, dancers and musicians rehearsed separately. As such, they fixed their own ideas on interpretation of the dance suite. At the end of the rehearsal, the musical performance was recorded, with the musicians not knowing the choreography. After this, the dancers joined the ensemble. First, musicians and dancers performed the dance together without communicating in advance. After this first joint performance, the dancers gave feedback and, together with the musicians, tried to come to an 'ideal' performance in which everybody agreed on the interpretation. Individual recordings of the musicians were made using contact microphones. Also the complete ensemble-sound was recorded and a video recording was made for control.

\subsection{Analysis}

Four versions of the piece were recorded: the instrumental version without dance and three versions with dance (one without and two with feedback). As we are mainly interested in the timing and tempo of the whole, we decided to base our analysis on the viol part as it plays continuously and articulates the meter most clearly. To determine the length of each event, we used a manual onset detection system using the program 'praat', which gives an automatic analysis of pitch and intensity as well as a spectrogram visualization, with parallel audio feedback. The use of this program makes it relatively easy to locate the onsets with a precision of a few milliseconds.

\subsection{Results}

The results of the timing analysis are summarized in fig.1. In the graph we clearly see the succession of three different parts. At the same time we see clear differences between the four versions. Three main changes were found in the analysis: a main change in tempo, differences in the endings of the first two parts and a change in the variability between the different versions.

Is it clear that the musicians immediately speed up their tempo in the first two movements when the dance is added. Even without oral communication (dance1) musicians feel that the dance demands a particular tempo. After communicating with the dancers, the tempo is adapted even more and the first two parts are performed even faster (dance2). After the second session the dancers were happy with the tempo for the first two parts. However, they thought the final part was performed too fast. Therefore a final version was recorded (dance3), where we see that the timing for the first two parts is very similar to the previous version, while the last part is played consistently slower.

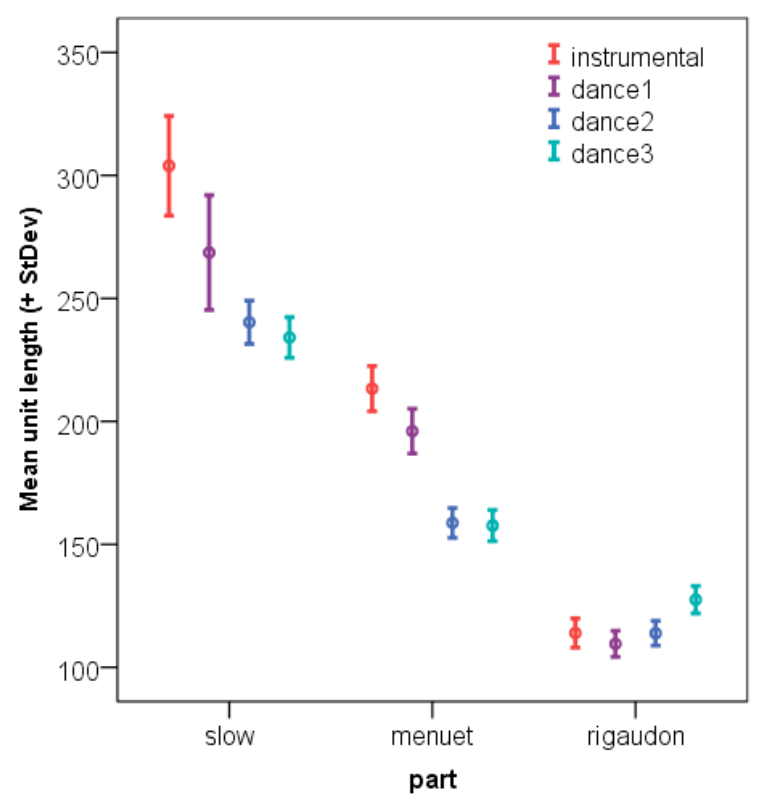

Figure 1: Timing for the viola da gamba in 'The Submission"

The second change considers the final retard in the first two parts. When recording the music without dance, the musicians tended to take a break between the parts. In the first version including dance, we see that this largely remains, as the musicians stopped and waited for the dancers to give a new start. However, the dancers perceive the choreography as a whole and need fluent transitions between the different parts, as the dance movement goes on.

A final effect is the lowering of the variance in the versions with dance, notably in the first two parts. Figure 1 shows the mean length of the unit in the three different parts for the four versions. Also in this case we can see a different attitude between dancers and musicians. Whereas musicians tend to exaggerate phrasing and rhythmic contrast, dancers actually prefer a more stable performance in which they can keep the cadence of their movement.

\section{EXPERIMENT 2: COURANTE AND SARABANDE IN MUSIC AND DANCE}

\subsection{Procedure}

The second experiment focuses on two popular dance types, the courante and the sarabande. The study consists of two parts: an 
analysis of tempo in existing performances and a study of actual dance performances with music of varying tempo.

First, the tempo of recorded sarabandes and courantes by French composers was analyzed. Pieces were collected using Spotify, based on a selection of representative composers of which the scores were available. The selection also contained different recordings of the same dance, if played by different performers, but only recordings on period instruments were retained. Based on the original time signature of each piece, the tempo was analyzed manually by tapping along with the music.

In the second part, we looked at choreographic performance to explore how dance movement is influenced by tempo. Based on surviving choreographies, a basic choreography for a courante and a sarabande were designed, containing the characteristic steps of these dances. To optimize the choreographies, the result was discussed with four dancing masters. For the courante, the melody of the dance suite 'La Duchesse' (La Duchesse, 1701) was used, for the sarabande, the music of 'La Royalle' (Pécour, 1712) was adopted. For both pieces an orchestration was made based on historical performance practice. These versions were transformed into MIDI files and rendered in a variety of tempi, starting from 80 BPM and moving up and down based on a division of the tempo-octave in 6 equal steps using a log- 2 scale. This resulted in the tempi seen in fig. 2 , which were applied to the quarter note of the melody of the sarabande, and the half note of the courante.

16 dancers participated in the experiment. They were asked to perform the choreography of the sarabande and courante on the music presented to them. The dancers performed the choreography twice in each tempo, which was recorded on video. After the two performances, they were asked to evaluate the tempo of the music on the basis of 1) the character or the dance, 2) fluency of their dance movements, 3) how they felt rhythmical cadence, 4) the difficulty to perform the choreography, 5) how comfortable they thought the tempo was on a 7-point Likert scale. Starting with the 'neutral' tempo of $80 \mathrm{BPM}$, alternately, a faster and a slower tempo were played until the dancers indicated that it was impossible to perform the choreography.

\subsection{Analysis}

\section{Analysis of music recordings}

944 recordings of music by Lully, Louis and François Couperin, Marais, Hotteterre, d'Anglebert, Chambonnières, Rameau and Jacquet de la Guerre were used to give a representative view of tempi in historically informed performances of French baroque music. The collection consisted of 507 sarabandes (mostly in 3/4, with some examples in $3 / 2$ or $6 / 4$ ) and 437 courantes (mostly in $3 / 2$, with some examples in $3 / 4$ ). Whereas the tempi of the sarabandes were very similar despite the metrical difference, the group of courantes in $3 / 4$ were clearly performed faster. As this meter does not correspond to the meter used in the dance study, 26 courantes were excluded from the analysis.

The distributions of tempi for both dances are very similar, with means of 68.86 and $68.47 \mathrm{bpm}$ for courante and sarabande respectively. The range of tempi is larger for the sarabande, which is reflected by a higher standard deviation (18.7 for the sarabande and 10.2 for the courante). The distribution is also more skewed, which indicates that there is quite a large group of slower sarabandes, but this is counterbalanced by a small group of fast pieces.

\section{Analysis of dance performance}

The analysis of the video recordings of the dance performances was done manually and comprised three criteria: the synchronization of the dancers to the music, their precision and smoothness. For the sarabande, every performance got a score on 16 , while the courante was assigned a score of 12 , in accordance with the number of bars in the dance.

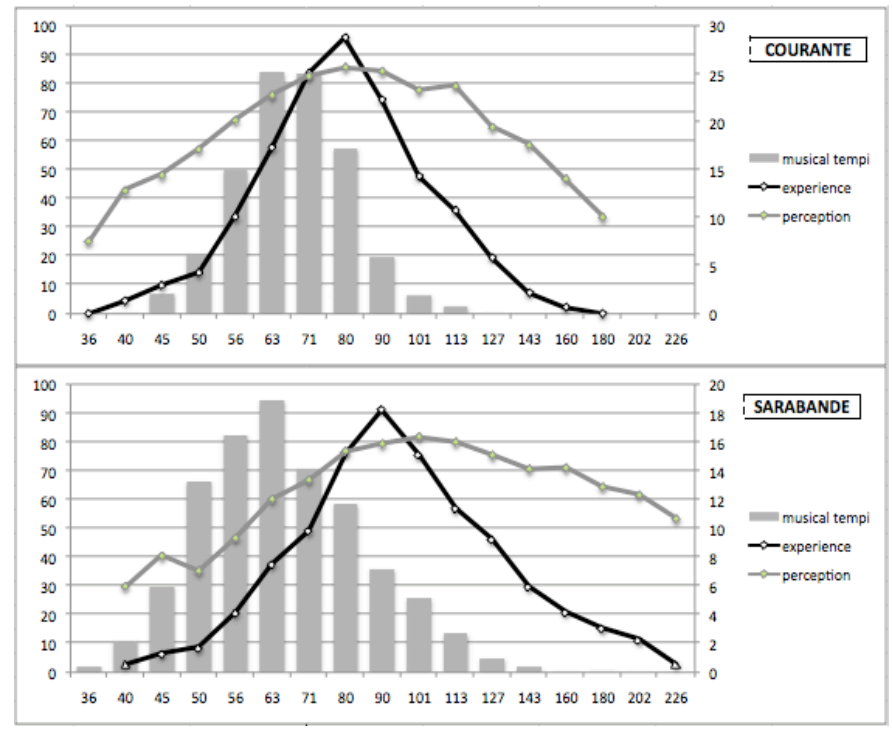

Figure 2: Tempi for the courante and sarabande in music recordings and dance performance

The results of the video analysis show that precision and smoothness score the highest for $80 \mathrm{bpm}$ with the courante (mean=88.9\%), and with the sarabande for $113 \mathrm{bpm}$ (mean=80.8\%). The peak is much sharper for the courante, the sarabande has high scores for al the tempi between 80 and 127 bpm. De dancers synchronize best at $90 \mathrm{bpm}$ with the courante (mean=88.9\%) and at $101 \mathrm{bpm}$ with the sarabande (mean=82.9\%). Also, nobody was able to perform the sarabande slower then 40 $\mathrm{bpm}$ and the courante faster than $180 \mathrm{bpm}$. The dancers themselves rated $80 \mathrm{bpm}$ as the optimal tempo for the courante, and $90 \mathrm{bpm}$ as optimal for the sarabande.

The results are summarized in figure 2, where we see the distribution of tempi found in the music recordings (grey bars), the average score of the evaluations by the dancers (experience, black line) and the average score of the smoothness and precision parameters from the video analysis (perception, grey line). 


\section{DISCUSSION AND CONCLUSIONS}

The results of the first experiment confirm that dance movement can have an actual influence on the interpretation of dance music by musicians. Verbal communication between dancers and musicians can help to generate a musical performance that fits the choreography best, but even when bodily communication alone is used during performance, musicians experience an influence of the dance movement on their interpretation, which mainly effects their tempo and timing.

However, lots of musicians are not aware of the corporeal aspects of Baroque dance music and hence, an essential part of this music is lost. The results of the second experiment show that the interpretation of the sarabande by musicians is in general slower than the tempo dancers prefer. A similar but less pronounced trend is observed for the interpretation of the courante. Moreover, the relationship of tempo between courante and sarabande as defined by the dance experiment is in accordance with the proportions of the time signatures $3 / 4$ en $3 / 2$ and the characteristics of these two dance types as described in historical sources of the Baroque period (d'Alembert, 1752; de Brossard, 1703; de Saint-Lambert, 1702; Freillon-Poncein, 1700; Masson, 1705; Montéclair, 1736; Muffat, 1698; Rameau, 1725; Rousseau, 1768). In the research field of historical music performance, the information gathered from dance and choreography could be of great importance for the realization of a historically correct interpretation.

On the other hand, the question still remains how strictly the character of the dance was maintained when there was no active dance practice involved. As already mentioned, court composers were aware of the aspects of dance performance, also when they composed concert music, but an evolution to more complex forms inevitable lead to compositional and interpretational freedom. Also, not all dances were commonly danced during the Baroque, which opens the question if dance movement did influence composition and performance in such cases. Nevertheless, collaborations between dancers and musicians can lead to new and fruitful insights in the puzzling language of Baroque Dance.

\section{ACKNOWLEGDEMENT}

We would like to thank Lieven Baert and Josephine Schreibers, the two dancers involved in the first experiment, and Stefaan Smagghe and Kersten Cottyn, the musicians who participated on the violin and harpsichord respectively.

Special thanks goes also to Guillaume Jablonka, Béatrice Massin, Dorothée Wortelboer and Johan Goessens, the four dancing Masters who thought us a lot and helped us with the choreography and the second experiment.

\section{REFERENCES}

Campbell, P.S. (1991). Rhythmic Movement and Public School Music Education: Conservative and Progressive Views of the Formative Years. Journal of Research in Music Education, 39(1), 12-22.

Cobau, J. (1984). The Preferred Pas de Menuet. Dance Research Journal, 16(2), 13-17.

Cyr, M. (1998). Performing Baroque music (R. G. Pauly Ed.). Portland: Amadeus press.

d'Alembert, J.1.R. (1752). Éléments de Musique théorique et pratique, suivant les Principes de M. Rameau. Paris: Jombert.

de Brossard, S. (Ed.) (1703) Dictionaire [sic.] de Musique (1st edition ed.). Paris: Ballard, Christophe.

de La Chapelle, J.-A. (1737). Les Vrais principes de la musique. Paris: Veuve Boivin.

de Saint-Lambert, M. (1702). Les Principes du clavecin contenant une explication exacte de tout ce qui concerne la tabulature \& le clavier. Paris: Ballard, Christophe.

Donington, R. (1989). The interpretation of early music: New revised edition. London: Faber and Faber.

Fabian, D., \& Schubert, E. (2004). Expressive Devices and Perceived Musical Character in 34 Performances of Variation 7 from Bach's Goldbergvariations. Musicae Scientiae, 7(1 suppl), 49-71.

Feuillet, R.A. (1700). Choregraphie: ou L'art de décrire la dance. Paris: Chez l'auteur et chez Michel Brunet.

Feuillet, R.A., \& Pécour, L.-G. (1704). Traité de la cadance. Recüeil de dances. Paris: Chez le sieur Feüillet.

Franko, M. (2011). Writing For The Body: Notation, Reconstruction, and Reinvention in Dance. Common Knowledge, 17(2), 321-334.

Freillon-Poncein, J.-P. (1700). La véritable manière à jouer en perfection du haut-bois. Paris: J.Collombat.

Harris-Warrick, R. (1992). Interpretation of Pendulum Markings for 18th-Century French Dance. Paper presented at the The marriage of music and dance: National Early Music Association.

Heijdemann, F. (1984). De tempo-aanduidingen bij L'Affilard en Pajot (d'Onzembray). In K. Vellekoop (Ed.), Tempo in de Achttiende Eeuw (pp. 26-36). Utrecht.

Hilton, W. (1977). A Dance for Kings: The 17th-Century French "Courante". Its Character, Step-Patterns, Metric and Proportional Foundations. Early Music, 5(2), 161-172.

Hilton, W. (1981). Dance and Music of Court and Theater: Selected Writings of Wendy Hilton: Pendragon Press. 
Hilton, W. (1986). Dances to Music by Jean-Baptiste Lully. Early Music, 14(1), 51-63.

Jerold, B. (2010). The French Time Devices Revisited. Dutch journal of music theory, 15(3), 169-189.

Kroemer, J. (2001). Le cronometre de Monsieur Feuillet. (PhD Dissertation), University of Vienna.

l'Affilard, M. (1705). Principes très faciles pour bien apprendre la musique, 5th edition. Paris: Christophe Ballard.

La Duchesse. (1701). Chorégraphie, par DESCAN, (14884). Bibliothèque nationale de France, Département des manuscrits.

Leman, M., Moelants, D., Varewyck, M., Styns, F., van Noorden, L., \& Martens, J.-P. (2013). Activating and Relaxing Music Entrains the Speed of Beat Synchronized Walking. PLoS ONE, 8(7), e67932.

Leman, M., \& Naveda, L. (2010). Basic Gestures as Spatiotemporal Reference Frames for Repetitive Dance/Music Patterns in Samba and Charleston. Music Perception: An Interdisciplinary Journal, 28(1), 71-91.

Little, M.E. (1975a). The Contribution of Dance Steps to Musical Analysis and Performance: "La Bourgogne". Journal of the American Musicological Society, 28(1), 112-124.

Little, M.E. (1975b). Dance under Louis XIV and XV: Some Implications for the Musician. Early Music, 3(4), 331-340.

Little, M.E., \& Jenne, N. (2001). Dance and the Music of J.S. Bach: Indiana University Press.

Loulié, É. (1696). Elements ou Principes de musique mis dans un nouvel ordre. Paris: Christophe Balard.

Maduell, M., \& Wing, A.M. (2007). The dynamics of ensemble: the case for flamenco. Psychology of Music, 35(4), 591-627.

Masson, C. (1705). Nouveau traité des règles pour la composition de la musique. Paris: Ballard, Christophe.

Meyerhöfer, D. (1996). Lichtenberg und die Sammlung wissentschaftlicher Geräte des Frankfurter Patriziers Johann Friedrich Armand von Uffenbach Lichtenberg Jahrbuch 1995. Saarbrücken.

Moelants, D. (2011). The Performance of Notes Inégales: The Influence of Tempo, Musical Structure, and Individual Performance Style on Expressive Timing. Music Perception: An Interdisciplinary Journal, 28(5), 449-460.
Moelants, D., Demey, M., Grachten, M., Wu, C.-F., \& Leman, M. (2012). The Influence of an Audience on Performers: A Comparison Between Rehearsal and Concert Using Audio, Video and Movement Data. Journal of New Music Research, 41(1), 67-78.

Montéclair, M.P. (1736). Principes de musique. Paris: veuve Boivin.

Muffat, G. (1698). Florilegium Secundum. Denkmäler der Tonkunst in Öterreich, (4). Vienna.

Pajot, L.-L. (1735). Description et usage d'un métromètre, ou machine pour battre les mesures \& les temps de toutes sortes d'airs. Histoire de l'Académie Royale des Sciences, 1732, 182-196.

Pécour, G.-L. (1712). La Royalle Nouveau recüeil de dance de bal et celle de ballet, contenant un très grand nombres ["sic"] des meillieures ["sic"] entrées de ballet (pp. 1-5). Paris: Gaudrau, M.

Phillips-Silver, J., \& Trainor, L.J. (2005). Feeling the Beat: Movement Influences Infant Rhythm Perception. Science, 308(5727), 1430.

Pierce, K. (1998). Dance Notation Systems in Late 17th-Century France. Early Music, 26(2), 287-299.

Qureshi, R.J. (1994). The influence of Baroque dance in the performance of Johann Sebastian Bach's Six Suites a Violoncello Senza Basso. (Doctoral Thesis), Rice University.

Rameau, P. (1725). Le Maître a danser. Paris: J. Villette.

Rousseau, J.-J. (1768). Dictionnaire de musique. Paris: la venue Duchesse.

Spitzer, J., \& Zaslaw, N. (2005). The Birth of the Orchestra : History of an Institution, 1650-1815: Oxford University Press, USA.

Thaut, M.H., \& Abiru, M. (2010). Rhythmic Auditory Stimulation in Rehabilitation of Movement Disorders: A Review Of Current Research. Music Perception: An Interdisciplinary Journal, 27(4), 263-269.

Van Biezen, J. (1984). Het tempo van de Franse Barokdansen. In K. Vellekoop (Ed.), Tempo in de Achttiende Eeuw (pp. 7-25). Utrecht. 